\title{
STUDI PENGGUNAAN PASIR LAUT SEBAGAI FILLER PADA CAMPURAN ASPHALT CONCRETE BINDER COURSE (AC-BC)
}

\author{
Trio Mareta Jaya ${ }^{1)}$, Samsul Bahri ${ }^{2}$, Makmun Reza Razali ${ }^{3)}$ \\ ${ }^{122) 3)}$ Program Studi Teknik Sipil, Fakultas Teknik UNIB, Jl. W. R. Supratman, \\ Kandang Limun, Bengkulu 38371, Telp. (0736)344087 \\ email: inersia@unib.ac.id
}

\begin{abstract}
Abstrak
Penelitian ini merupakan inovasi baru untuk menemukan bahan alternatif pengganti filler semen Portland dengan menggunakan pasir laut. Penelitian ini menguji pengaruh penggunaan pasir laut pada campuran Asphalt Concrete Binder Course (AC-BC) dengan variasi pergantian pasir laut sebesar 25\%; 50\%; 75\%, dan $100 \%$. Penelitian ini merupakan studi eksperimen di laboratorium dengan menggunakan metode pengujian Marshall test berupa stabilitas, kelelehan, Marshall quotient (MQ), VMA, VFA, dan VIM. Untuk mendukung hasil pengujian dilakukan penelitian di laboratorium meliputi pengujian fisis aspal, agregat, dan filler. Hasil dari penelitian ini diperoleh nilai karakteristik Marshall untuk VMA yang terbaik berada pada variasi $100 \%$ sebesar $16,89 \%$; nilai VFA tertinggi pada variasi $100 \%$ sebesar $81,78 \%$; nilai VIM yang terbaik berada pada kondisi normal sebesar $4,10 \%$; nilai kepadatan terbaik pada kondisi normal sebesar 2,35 T/m³ ; nilai stabilitas tertinggi pada kondisi normal sebesar 1519,23 kg ; nilai flow yang terbaik berada di variasi $25 \%$ sebesar $4,52 \mathrm{~mm}$; nilai MQ yang yang tertinggi berada di kondisi normal sebesar $453,21 \mathrm{~kg} / \mathrm{mm}$. Penggunaan pasir laut sebagai filler pada semua variasi dapat digunakan walaupun tidak semua variabel karakteristik Marshall yang nilainya tinggi dibandingkan dengan kondisi normal tanpa penggantian. Semakin banyak pasir laut yang digunakan sebagai filler, maka semakin banyak kadar aspal yang dibutuhkan dalam suatu campuran, pada penelitian ini kadar aspal variasi $100 \%$ meningkat $2 \%$ jika dibandingkan dengan kondisi tanpa pergantian.
\end{abstract}

Kata kunci: AC-BC, pasir laut, filler

\begin{abstract}
This research is a new innovation to find alternative material to replace Portland cement filler by using sea sand. This study examined the effect of sea sand usage on Asphalt Concrete Binder Course $(A C-B C)$ mixture with sea shifting variation of $25 \% ; 50 \% ; 75 \%$, and $100 \%$. This research is an experimental study in laboratory by using Marshall test method in the form of stability, melting, Marshall quotient (MQ), VMA, VFA, and VIM. To support the test results conducted in the laboratory research including physical examination of asphalt, aggregate, and filler. The results of this study obtained the value of Marshall characteristics for the best VMA is at $100 \%$ variation of $16.89 \%$; The highest VFA value at $100 \%$ variation of $81,78 \%$; The best VIM values are at normal conditions of $4.10 \%$; The best density value in normal condition is $2.35 \mathrm{~T} / \mathrm{m}^{3}$; The highest stability value under normal conditions of $1519.23 \mathrm{~kg}$; The best flow rate is in the $25 \%$ variation of $4.52 \mathrm{~mm}$; The highest $M Q$ values are in normal condition of 453.21 $\mathrm{kg} / \mathrm{mm}$. The use of sea sand as filler in all variations can be used although not all Marshall characteristic variables are high in value compared with normal conditions without
\end{abstract}


replacement. The more sea sand used as filler, the more asphalt content needed in a mixture, in this study the asphalt content increased $2 \%$ when compared with the condition without change

Keywords: $A C-B C$, sea sand, filler

\section{PENDAHULUAN}

Provinsi Bengkulu merupakan wilayah yang sebagian besar menghadap ke Samudera Hindia dengan panjang pantai mencapai 525 $\mathrm{km}$ dan memiliki luas laut teritorial sebesar $53.000 \mathrm{~km}^{2}$. Lingkungan geografis tersebut menjadikan ketersediaan pasir laut di Provinsi Bengkulu sangat berlimpah. Butiran pasir laut umumnya berukuran antara 0,0625 sampai 2 milimeter. Materi pembentuk pasir laut adalah silika, tetapi di beberapa pantai tropis dan subtropis umumnya dibentuk dari batu kapur.

Aspal beton (Asphalt Concrete) di Indonesia dikenal dengan Laston (Lapisan Aspal Beton) yaitu lapis permukaan struktural atau lapis pondasi atas. Aspal beton terdiri atas 3 (tiga) macam lapisan, yaitu Laston Lapis Aus (Asphalt ConcreteWearing Course atau AC-WC), Laston Lapis Permukaan Antara (Asphalt ConcreteBinder Course atau AC-BC) dan Laston Lapis Pondasi (Asphalt Concrete-Base atau AC-Base). Ketebalan nominal minimum masing-masing $4 \mathrm{Cm}, 6 \mathrm{Cm}$, dan 7,5 Cm.

\section{Aspal beton}

Menurut Bina Marga (2007), Aspal beton merupakan campuran yang homogen antara agregat (agregat kasar, agregat halus dan bahan pengisi atau filler) dan aspal sebagai bahan pengikat yang mempunyai gradasi tertentu. Proses pembuatannya dilakukan dengan cara dicampur, dihamparkan dan dipadatkan pada suhu tertentu untuk menerima beban lalu lintas yang tinggi.

\section{Material penyusun perkerasan}

Perkerasan jalan merupakan campuran dari agregat kasar, agregat halus, aspal dan filller (bahan pengisi), dengan nilai perbandingan yang telah direncanankan. Bahan-bahan campuran aspal harus memenuhi ketentuan yang disyaratkan dalam spesifikasi umum yang dikeluarkan oleh Kementerian Pekerjaan Umum Direktorat Jenderal Bina Marga 2010 Revisi 3 Divisi 6.

\section{Agregat}

Menurut Kementrian Pekerjaan Umum Direktorat Jenderal Bina Marga 2010 Revisi 3 Divisi 6 agregat secara umum harus memenuhi spesifikasi:

1) Agregat yang digunakan harus sedemikian rupa agar campuran beraspal, yang proporsinya dibuat sesuai dengan rumusan campuran.

2) Pada pemilihan sumber agregat, harus memperhitungkan penyerapan aspal oleh agregat.

3) Penyerapan air oleh agregat maksimum $3 \%$.

4) Berat jenis (spesific gravity) agregat kasar dan halus tidah boleh berbeda lebih dari 0,2 .

\section{Bahan pengisi (filler)}

Menurut Kementerian Pekerjaan Umum Direktorat Jenderal Bina Marga 2010 Revisi 3 Divisi 6 bahan pengisi (filler) harus memenuhi spesifikasi:

1) Bahan pengisi (filler) yang ditambahkan terdiri dari debu batu kapur, debu kapur padam, semen, atau ,mineral.

2) Bahan pengisi (filler) yang ditambahkan harus kering dan bebas dari gumpalangumpalan dan bila diuji dengan pengayakan harus mengandung bahan yang lolos ayakan No.200 (75 micron) tidak kurang dari $75 \%$ terhadap baratnya kecuali untuk mineral Asbuton. 
3) Kapur yang tidak terhidrasi maupun hanya terhidrasi sebagian, tidak dapat digunkan sebagai bahan pengisi (filler).

4) Semua campuran beraspal harus mengandung bahan pengisi (filler) minimal $1 \%$ dari berat total agregat.

\section{Aspal}

Menurut Sukirman (1999) aspal didefinisikan sebagai material bewarna hitam atau coklat tua, pada temperatur ruang berbentuk padat sampai agak padat. Jika dipanaskan sampai suatu temperatur tertentu aspal dapat menjadi lunak/cair sehingga dapat membungkus partikel agregat pada waktu pembuatan aspal beton. Jika temperatur mulai turun, aspal akan mengeras dan mengikat agregat pada tempatnya.

\section{Pasir laut}

Pasir laut merupakan salah satu jenis material agregat yang memiliki ketersedian dalam jumlah berlimpah. Berdasarkan pengertian geologi, yang dimaksud dengan pasir laut adalah segala material (sedimen) yang berukuran pasir yang karena proses transportasi akhirnya terendapkan dan terakumulasi dalam sedimen di dasar laut.

Sifat volumetrik campuran aspal beton Secara analitis dapat ditentukan sifat volumetrik dari beton aspal padat, baik yang dipadatkan di laboratorium, maupun di lapangan (Tenriajeng, 2007).

1) VIM (Voids In Mixture) adalah volume pori/rongga di antara partikel agregat yang diselimuti aspal dalam campuran yang telah dipadatkan, yang dinyatakan dalam (\%) terhadap volume total campuran.

2) VMA (Voids In Mineral Aggregat) adalah volume pori di antara partikel agregat dalam campuran yang telah dipadatkan, termasuk pori yang terisi oleh aspal, yang dinyatakan dalam (\%) terhadap volume total campuran.
3) VFA (Voids Filled By Asphalt) pori beton aspal padat yang terisi oleh aspal atau selimut aspal. Banyaknya pori-pori antara butir agregat(VMA) didalam beton aspal padat, yang terisi oleh aspaldinyatakan sebagai VMA. Persentase pori antara butir agregat yang terisi aspal dinamakan VFA. Jadi, VFA adalah bagian dari VMA yang terisi aspal, tidak termasuk di dalamnya aspal yang terabsorbsi oleh masing-masing butir agregat.

\section{Pengujian Marshall}

Pemeriksaan Marshall digunakan untuk menentukan ketahanan terhadap kelelehan dari campuran aspal dan agregat. Kelelehan plastis adalah keadaan perubahan bentuk campuran yang terjadi akibat beban sampai batas runtuh yang dinyatakan dalam " $\mathrm{mm}$ atau 0,01 ". Ketentuan sifat-sifat campuran aspal beton (laston) menurut spesifikasi BM.2010 dapat dilihat pada Tabel 1.

Tabel 1. Ketentuan sifat-sifat laston

\begin{tabular}{|c|c|c|c|c|}
\hline \multirow{2}{*}{\multicolumn{2}{|c|}{ Sifat-sifat campuran }} & \multicolumn{3}{|c|}{ Laston } \\
\hline & & WC & $\mathrm{BC}$ & Base \\
\hline $\begin{array}{l}\text { Penyerapan } \\
\text { Aspal (\%) }\end{array}$ & Max & \multicolumn{3}{|c|}{1,2} \\
\hline \multicolumn{2}{|c|}{$\begin{array}{l}\text { Jumlah tumbukan per } \\
\text { bidang }\end{array}$} & \multicolumn{2}{|c|}{75} & 112 \\
\hline \multirow{2}{*}{ VIM (\%) } & Min & \multicolumn{3}{|c|}{3,5} \\
\hline & Max & \multicolumn{3}{|c|}{5,5} \\
\hline VFA (\%) & Min & 15 & 14 & 13 \\
\hline VMA (\%) & Min & 65 & 63 & 60 \\
\hline \multirow{2}{*}{$\begin{array}{l}\text { Stabilitas } \\
\text { Marshall } \\
(\mathrm{kg})\end{array}$} & Min & \multicolumn{2}{|c|}{800} & 1500 \\
\hline & Max & \multicolumn{2}{|c|}{ - } & - \\
\hline Flow (mm) & Min & \multicolumn{2}{|c|}{3} & 5 \\
\hline $\begin{array}{l}\mathrm{MQ} \\
(\mathrm{kg} / \mathrm{mm})\end{array}$ & Min & \multicolumn{2}{|l|}{250} & 300 \\
\hline $\begin{array}{l}\text { Stabilitas } \\
\text { Marshall } \\
\text { sisa (\%) } \\
\text { setelah } \\
\text { perendaman } \\
24 \text { jam, } \\
60^{\circ} \mathrm{C} \\
\end{array}$ & Min & \multicolumn{3}{|c|}{75} \\
\hline Refusal & Min & \multicolumn{3}{|c|}{2,5} \\
\hline
\end{tabular}




\section{METODE PENELITIAN}

Penelitian ini berupa pembuatan benda uji, perawatan dan pengujian benda uji dilakukan di Laboratorium Transportasi Program Studi Teknik Sipil Fakultas Teknik Universitas Bengkulu. Penelitian ini menggunakan campuran Asphalt Concrete Binder Course $(A C-B C)$ yang terdiri dari agregat kasar, agregat halus, aspal, filler, dan pasir laut dengan pengujian Marshall test. Variasi penggantian filler dengan pasir laut sebesar 25\%, 50\%, 75\% dan $100 \%$. Aspal yang digunakan aspal penetrasi 60/70.

\section{Rancangan campuran aspal}

Rancangan campuran aspal menggunakan metode Marshall. Metode ini lebih mudah untuk diaplikasikan untuk rancangan campuran aspal beton bergradasi baik. Langkah-langkah rancangan untuk menggunakan metode ini adalah sebagai berikut:

1. Mempelajari spesifikasi gradasi agregat campuran yang diinginkan dari Spesifikasi Bina Marga 2010 Revisi 3 Divisi 6.

2. Merancang proporsi agregat, proporsi ini ditentukan secara analitis dimana proporsi agregat tersebut dipilih dari gradasi yang sesuai Spesifikasi Bina Marga 2010. Prinsip kerja metode analitis ini adalah tentukan gradasi agregat yang dipilih kemudian menghitung jumlah butiran yang lolos dan tertahan saringan no.4.

3. Mendapatkan kadar aspal total dalam campuran menggunakan rumus $\mathrm{P}=$ $0,035(\% \mathrm{CA})+0,045(\% \mathrm{FA})+0,18$ $($ filler $)+1$. Dari perhitungan diperoleh kadar aspal rencana $\mathrm{P}$ dengan dua variasi kadar aspal diatas $\mathrm{P}$ dan dua variasi kadar aspal dibawah $\mathrm{P}(-1,0 \% ;-0,5 \%$; ; $+0,5 \% ;+1 \%$ ).

4. Menggambarkan hasil uji Marshall untuk mendapatkan kadar aspal optimum.
5. Membuat benda uji dengan komposisi penggantian filler dengan pasir laut yaitu sebesar 25\%, 50\%, 75\%, $100 \%$ dan aspal normal tanpa penggantian agregat untuk mendapatkan kadar aspal optimum (KAO).

6. Hubungan nilai karakteristik Marshall dengan variasi bahan tambahan tersebut, dilakukan perendaman benda uji selama 24 jam dan selanjutnya melakukan pengujian dengan alat uji Marshall Test.

\section{Pembuatan benda uji}

Terdapat tiga bahan campuran yang akan digunakan dalam campuran benda uji, yaitu agregat kasar, agregat halus, dan filler terdiri dari pergantian pasir laut. Agregat dan filler ditimbang sesuai fraksi ukurannya berdasarkan gradasi yang diinginkan. Berat total agregat campuran adalah berat agregat yang dapat menghasilkan satu benda uji padat setinggi $6,35 \mathrm{~cm}$ dengan diameter 10,2 $\mathrm{cm}$. Umumnya berat agregat campuran adalah 1200 gram. Prosedur pembuatan benda uji untuk campuran aspal adalah:

1. Komposisi pergantian filler

Filler merupakan agregat yang lolos ayakan no.200 dilakukan penggantian perfraksi saringan sebesar variasi yang direncanakan yaitu $25 \%, 50 \%, 75 \%$ dan $100 \%$. Jadi nanti setiap satu sampel benda uji akan terdiri dari agregat kasar, agregat halus, dan filler dilakukan penggantian sebesar variasi yang ditentukan. Sampel benda uji dibuat sebanyak 3 buah sampel per variasi pergantiaan filler menggunakan pasir laut.

2. Persiapan benda uji

Bersihkan bahan untuk benda uji, kemudian keringkan dalam oven pada suhu $110^{\circ} \mathrm{C}$ selama 24 jam. Setelah itu, pisahkan agregat kasar, agregat halus, dan filler ke dalam wadah berupa nampan/loyang agar mudah pada saat pengambilan. Bersihkan cetakan benda uji lalu buat alas benda uji sesuai dengan 
diameter cetakan. Sebelum penuangan, bagian dalam cetakan dilapisi oli agar benda uji tidak melekat dengan cetakan dan mempermudah pengeluaran benda uji dari cetakan.

3. Pembuatan campuran

Panaskan agregat dan filler yang diperlukan dengan cara disangrai hingga dengan suhu $110^{\circ} \mathrm{C}$. Panaskan juga aspal dengan kadar aspal yang diperlukan dari komposisi campuran yang telah didapat dengan suhu $110^{\circ} \mathrm{C}$, setelah itu tuangkan aspal sesuai jumlah yang dibutuhkan ke dalam agregat dan filler. Aduk campuran hingga merata.

4. Pemadatan campuran

Setelah campuran aspal mencapai suhu $160^{\circ} \mathrm{C}$, pindahkan kedalam cetakan yang telah dilapisi kertas saring yang bagian dasarnya telah dilapisi kertas dan ditusuk-tusuk pada pinggir cetakan dan bagian tengah cetakan yang telah terisi campuran. Lepaskan leher cetakan, ratakan permukaan campuran dengan sedok semen sehingga menjadi sedikit cembung. Letakan cetakan diatas alat pemadat kemudian ditumbuk sebanyak 75 kali. Setelah selesai cetakan dibalik dan dilakukan penumbukan kembali sebanyak 75 kali.

5. Perawatan benda uji

Benda uji yang telah dipadatkan dikeluarkan dari cetakan dengan dongkrak hidrolik (extruder) dengan meletakkan pelat pengeluar benda uji pada bagian atas cetakan dan lepaskan pelat dasar cetakan. Keluarkan benda uji dengan hati-hati dan letakkan pada permukaan yang rata untuk dibiarkan selama 1 hari pada suhu ruang hingga mengeras.

\section{Pengujian campuran}

Benda uji yang yang telah dicetak selanjutnya ditimbang dan diletakkan diatas permukaan yang rata selama kira-kira 24 jam pada temperatur ruangan, selanjutnya ditimbang lagi dalam keadaan kering permukaan jenuh. Kemudian benda uji direndam dalam waterbath pada suhu $60^{\circ} \mathrm{C}$ selama 30 menit. Benda uji segera mungkin dilakukan pengujian dengan alat Marshall dan harus dalam waktu tidak lebih dari 30 detik sejak diambil dari waterbath. Pembacaan untuk stabilitas dilakukan pada pembebanan tertinggi dalam $\mathrm{kg}$ pada arloji dan flow dicatat pada pembebanan puncak tersebut dalam satuan $0,1 \mathrm{~mm}$.

\section{HASIL DAN PEMBAHASAN}

\section{Hasil pengujian karakteristik Marshall mencari KAO}

Berdasarkan dari hasil pengujian karakteristik Marshall didapat bahwa semua variasi yang memenuhi persyaratan dari Kementerian Pekerjaan Umum Direktorat Jenderal Bina Marga 2010 Revisi 3 dengan kadar aspal yang berbeda-beda. Kadar Aspal Optimum (KAO) yang didapat yaitu P-1 $(4,775 \%)$ untuk aspal kondisi normal dan variasi $25 \%, \mathrm{P}(5,775 \%)$ untuk variasi $50 \%$, $\mathrm{P}+0,5(6,275 \%)$ untuk variasi $75 \%$, dan $\mathrm{P}+1$ $(6,775 \%)$ untuk variasi $100 \%$.

\section{Hasil pengujian karakteristik Marshall kondisi KAO}

Nilai untuk hasil pengujian karakteristik Marshall pada kondisi KAO dapat dilihat sebagai berikut:

a. Nilai VMA yang didapat yaitu $14,16 \%$ untuk kondisi normal, 14,05 \% untuk variasi $25 \%, 15,13$ untuk variasi $50 \%$, 16,03 untuk variasi $75 \%, 16,89 \%$ untuk variasi $100 \%$.

b. Nilai VFA yang didapat sebesar 71,12\% untuk kondisi normal, 71,69 \% untuk variasi $25 \%, 79,49 \%$ untuk variasi 50 $\%, 80,66 \%$ untuk variasi $75 \%, 81,78 \%$ untuk variasi $100 \%$.

c. Nilai VIM yang didapat sebesar $4,10 \%$ untuk kondisi normal, 3,98 \% untuk variasi $25 \%, 3,10$ untuk variasi $50 \%$, 3,10 untuk variasi $75 \%, 3,08 \%$ untuk variasi $100 \%$. 
d. Nilai Density yang didapat sebesar 2,35 $\mathrm{T} / \mathrm{m}^{3}$ untuk kondisi normal, $2,35 \mathrm{~T} / \mathrm{m}^{3}$ untuk variasi $25 \%, 2,34 \mathrm{~T} / \mathrm{m}^{3}$ untuk variasi $50 \%, 2,33 \mathrm{~T} / \mathrm{m}^{3}$ untuk variasi 75 $\%, 2,32 \mathrm{~T} / \mathrm{m}^{3}$ untuk variasi $100 \%$.

e. Nilai Flow yang didapat sebesar 3,36 mm untuk kondisi normal, 4,52 mm untuk variasi $25 \%, 3,57 \mathrm{~mm}$ untuk variasi $50 \%, 3,73 \mathrm{~mm}$ untuk variasi 75 $\%, 3,60 \mathrm{~mm}$ untuk variasi $100 \%$.

f. Nilai Stabilitas yang didapat sebesar $1519,23 \mathrm{~kg}$ untuk kondisi normal, $1191,95 \mathrm{~kg}$ untuk variasi $25 \%, 1050,89$ $\mathrm{kg}$ untuk variasi $50 \%, 1052,84 \mathrm{~kg}$ untuk variasi $75 \%, 949,65$ untuk variasi 100 $\%$.

g. Nilai Marshall Quotient yang didapat sebesar 453,21 $\mathrm{kg} / \mathrm{mm}$ untuk kondisi normal, $264,37 \mathrm{~kg} / \mathrm{mm}$ untuk variasi 25 $\%, 296,98 \mathrm{~kg} / \mathrm{mm}$ untuk variasi $50 \%$, $282,33 \mathrm{~kg} / \mathrm{mm}$ untuk variasi $75 \%$, $265,93 \mathrm{~kg} / \mathrm{mm}$ untuk variasi $100 \%$.

Berdasarkan hasil pengujian nilai-nilai karakteristik Marshall semuanya masih memenuhi batas minimum dan maksimum dari spesifikasi Kementerian Pekerjaan Umum Direktorat Jenderal Bina Marga 2010 Revisi 3.

\section{KESIMPULAN}

Berdasarkan penelitian yang telah dilakukan dengan pergantian filler dengan pasir laut, dapat disimpulkan:

1. Hasil pengujian pada pergantian filler dengan pasir laut pada campuran AC$\mathrm{BC}$, didapat semua hasil dengan benda uji KAO tepilih telah memenuhi syarat Spesifikasi Umum Bina Marga 2010 Revisi 3.

2. Hasil pengujian pada pergantian filler dengan pasir laut pada campuran AC$\mathrm{BC}$, mengalami penurunan nilai terhadap Karakteristik Marshall. Hal tersebut dapat dilihat dari nilai karakteristik Marshall untuk variasi pergantian tidak lebih unggul dari nilai karakteristik Marshall dengan filler normal, tetapi pada campuran variasi pergantian $100 \%$ beberapa hasil lebih unggul dibandingkan dengan kondisi normal. Nilai VMA dan VFA terbaik berada pada variasi $100 \%$, nilai VIM, Density, Stabilitas, dan Marshall Quoentient terbaik berada pada kondisi normal, nilai flow terbaik berada pada variasi $25 \%$.

3. Semakin banyak kadar pasir laut yang digunkan, maka semakin banyak kadar aspal yang dibutuhkan dalam suatu campuran

\section{DAFTAR PUSTAKA}

Kementerian Pekerjaan Umum Direktorat Jenderal Bina Marga, 2010, Spesifikasi Umum Bidang Jalan dan Jembatan, Revisi 3, Divisi VI , Jakarta.

Sukirman, S., 1999, Perkerasan Lentur Jalan Raya, Nova, Bandung.

Suprapto, T., 2004, Bahan dan Struktur Jalan Raya, KMTS FT UGM, Yogyakarta.

Tenriajeng, A.T., 2007, Rekayasa Jalan

Raya-2, Gunadarma, Jakarta. 